\title{
GRG Update: DDW 2014
}

\author{
Barbara Jung
}

Accepted: 6 June 2014/ Published online: 13 June 2014

(C) Springer Science+Business Media New York 2014

It is the time of year where we would like to take the opportunity to update the readership of Digestive Diseases and Sciences on the past year's Gastroenterology Research Group (GRG) activities. First off, we want to thank all of the members and speakers for their participations in the 2014 GRG Spring Symposium held during Digestive Disease Week on Sunday, May 4, 2014 at McCormick Place Convention Center is Chicago, IL, USA. The symposium was entitled "Metabolomics and Gastrointestinal Disease" and was chaired by Drs. William H. Grady, Andrew T. Chan and Barbara H. Jung. Three excellent lectures were presented:

1. Chi V. Dang, MD, PhD, Johns Hopkins University: "Metabolomics and Cancer"

2. Arun J. Sanyal, MD, Virginia Commonwealth University: "Metabolomics and Liver Disease"

3. Eugene B. Chang, MD, University of Chicago: "Metabolomics and the Gut Microbiome"

\section{GRG/AGA Young Investigator Awards and Fellow Travel Awards}

The central mission of the GRG is to foster, support, and promote the careers of young investigators (physician-scientist and doctoral scientists) who have research programs focused on the study of GI and liver disease. In order to advance this mission, the GRG recognizes the exceptional

B. Jung ( $\varangle)$

Division of Gastroenterology and Hepatology, University of Illinois at Chicago, 840 South Wood Street, 738A CSB, Chicago, IL 60612, USA

e-mail: bjung@uic.edu achievements of investigators conducting GI and Hepatology research with the Young Investigator Awards for Clinical Science and for Basic Science Research. Moreover, the GRG grants travel awards and an award for the Best Abstract of the Year from the pool of the eight abstracts selected for travel awards. Given the outstanding nature of this year's applications, we selected two of the travel awardees to receive the Best Abstract of the Year award. The exceptionally talented applicant pool also increased the difficulty of selecting the four awardees described below, who were recognized at the GRG Symposium by Dr. Chan.

The GRG is pleased to announce the awardees.

\section{Young Investigator Award for Clinical Sciences Research: Ashwin N. Ananthakrishnan, MBBS, MPH}

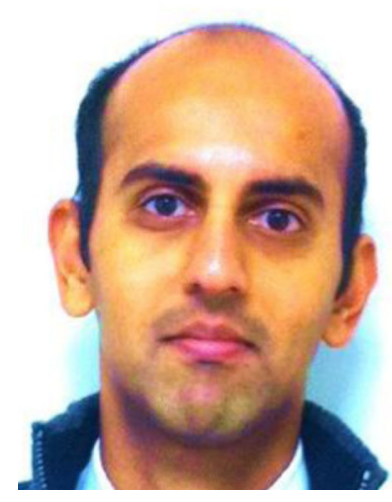

Dr. Ananthakrishnan is a junior faculty member in the Gastroenterology Department of Medicine at Massachusetts 
General Hospital of Harvard University, where he is establishing a world-class clinical research program focused on inflammatory bowel diseases including Crohn's disease and ulcerative colitis. He received his medical degree at the Jawaharlal Institute of Post-Graduate Medical Education and Research in India and an MPH from the Johns Hopkins University School of Public Health. He completed residency and Gastroenterology fellowship at the Medical College of Wisconsin before joining the Gastroenterology Unit at Massachusetts General Hospital and Harvard University as an Assistant Professor.

Dr. Ananthakrishnan's research focuses on the epidemiology and outcomes of inflammatory bowel diseases including the influencers of genetics and the environment in disease progression and natural history. He has authored over 109 original publications in leading academic journals including Gastroenterology, Gut, and Annals of Internal Medicine. He has received research support from an American Gastroenterological Association (AGA) Elsevier Pilot Award and an AGA Research scholar award, and is currently supported by a K23 award from the National Institutes of Health to pursue his studies.

\section{Young Investigator Award for Basic Science Research: Yatrik M. Shah, PhD}

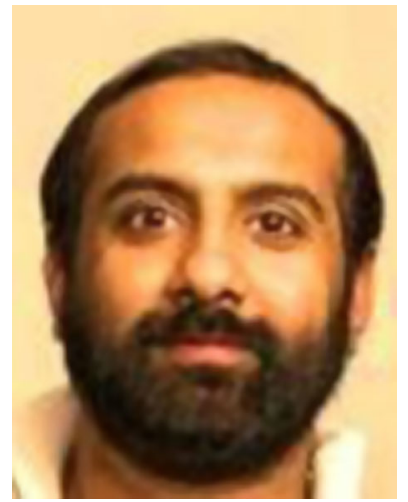

Dr. Shah is an Assistant Professor based in the Department of Molecular and Integrative Physiology and the Department of Internal Medicine, Division of Gastroenterology at the University of Michigan. In a relatively short time, Dr. Shah has established a robust research program investigating the molecular mechanisms by which oxygen sensing transcriptions factors, such as hypoxia inducible factor (HIF), regulate gastrointestinal homeostasis, inflammation and cancer. He has developed transgenic mouse models to study the role of hypoxia in iron metabolism and the role of hypoxia in the progression of colon cancer to pursue a recent observation that colon cancer cells are addicted to high intracellular levels of iron.

Dr. Shah completed his undergraduate training in biology at Bowling Green State University and his $\mathrm{PhD}$ in biochemistry at the University of Toledo. During his postdoctoral studies at the National Institutes of Health, Dr. Shah was mentored by Dr. Frank J. Gonzalez, in the Laboratory of Metabolism of the Center for Cancer Research at the National Cancer Institute where he employed metabolomics to the study of gastroenterology. His career has rocketed since being appointed as Assistant Professor at the University of Michigan. His high regard by the gastroenterology community is evidenced by his appointment to the editorial board of Gastroenterology.

\section{GRG Fellow Travel Abstract of the Year: Ivy Ka Man Law, PhD}

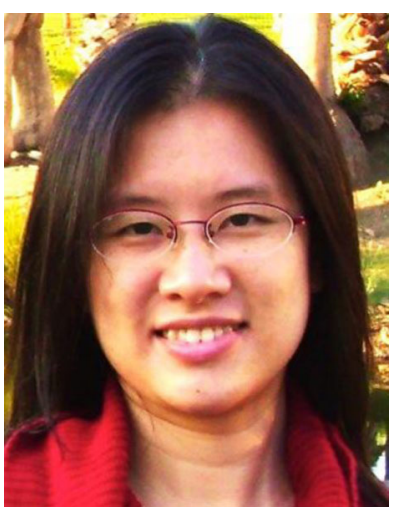

Dr. Law, a post-doctoral fellow in the Division of Digestive Diseases at the University of California Los Angeles, was awarded one of the abstracts of the year award for innovative research elucidating the mechanism by which microRNA-133a (miR-133a) regulates neurotensin signaling in models of colitis. She observed that miR-133a/aftiphilin interactions regulate neurotensin stimulated proinflammatory response in human colonic epithelial cells. In contrast, silencing miR-133a reduces cytokine expression and inflammation in mouse colitis. Therefore targeting miR-133a may represent a novel therapeutic approach for the treatment of inflammatory bowel disease. 
GRG Fellow Travel Abstract of the Year: Maxime Mahe, MS. PhD

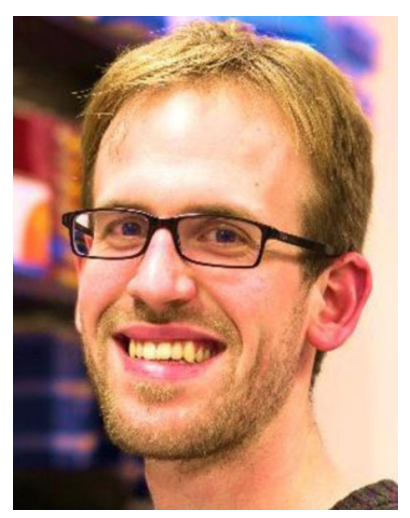

Dr. Mahe, a post-doctoral fellow at the Intestinal Rehabilitation Center at Cincinnati Children's Hospital, was awarded one of the abstracts of the year award for groundbreaking research on understanding the molecular basis for intestinal stem cell regionalization in murine and human intestinal stem cells. Dr. Mahe observed differential gene expression in intestinal stem cells based on regional location and further this intestinal regional identity is enforced by differential chromatin marks suggesting that an epigenomic state maintains the regional identity within the intestinal stem cells. These observations may provide the foundation for understanding the development of common diseases, such as Crohn's disease, in the distal small bowel as opposed to the proximal small bowel.

In closing, planning for the 2015 GRG Spring Symposium is currently underway. For information about the GRG Awards and other GRG activities, please visit our website www.gastroresearch.org.

We also encourage members of the GRG to submit original clinical and basic science manuscripts to DDS. Finally, we look forward to ongoing support of the GRG's senior mentors of young investigators' submission of up-todate translational research reviews to DDS as a means for GRG to advance its mission in GI and Hepatology research. 